\title{
The increasing frequency of intravenous drug abuse-associated spinal epidural abscesses: a case series
}

\author{
Anthony M. DiGiorgio, DO, MHA, ${ }^{1}$ Rachel Stein, BS, ${ }^{2}$ Kevin D. Morrow, MD, ${ }^{1}$ \\ Jared M. Robichaux, MD, ${ }^{1}$ Clifford L. Crutcher II, MD, ${ }^{1}$ and Gabriel C. Tender, MD1 \\ 1'Department of Neurosurgery, Louisiana State University Health Sciences Center, New Orleans, Louisiana; and ${ }^{2}$ School of \\ Medicine, Edward Via College of Osteopathic Medicine, Spartanburg, South Carolina
}

\begin{abstract}
OBJECTIVE Few studies have been published specifically examining intravenous drug abuse (IVDA)-associated spinal epidural abscesses (SEAs), an unfortunate sequela of the opioid crisis in the United States. Here, the authors examined a series of patients with IVDA-associated SEAs in order to shed light on this challenging disease entity.

METHODS This study is a retrospective chart review of patients presenting with IVDA-associated SEAs at the authors' institution from 2013 to 2018, spanning the statewide implementation of opioid-prescribing restrictions.

RESULTS A total of 45 patients presented with IVDA-associated SEAs; $46.5 \%$ presented with a neurological deficit. Thirty-one patients underwent surgery for neurological deficit, failure of medical therapy, or both. Nineteen surgical patients underwent a fusion procedure along with decompression. The complication rate was $41.9 \%$, and the mortality rate was $6.7 \%$. The average length of stay was 27.6 days. Patients who underwent surgery within 24 hours of onset of neurological symptoms trended toward more improvement in their American Spinal Cord Association Impairment Scale grade than those who did not (0.5 vs $-0.2, p=0.068)$. Methicillin-resistant Staphylococcus aureus was isolated as the causative pathogen in $57.8 \%$ of patients. Twenty-three patients $(51.5 \%)$ kept their scheduled clinic follow-up appointments. Of the fusion patients with adequate follow-up, 5 showed bony arthrodesis and 3 had pseudarthrosis. The rate of IVDA-associated SEAs increased after opioid-prescribing restrictions were put in place, from 0.54 cases per month to 1.15 cases per month $(p=0.017)$.
\end{abstract}

CONCLUSIONS Patients with IVDA-associated SEAs are challenging to treat, with high complication rates and poor follow-up. This disease is increasing in frequency, and opioid-prescribing restrictions did not slow that rise. Community outreach to promote prevention, early medical attention, and medication compliance would benefit this largely publicly funded patient population.

https://thejns.org/doi/abs/10.3171/2018.10.FOCUS18449

KEYWORDS intravenous drugs; epidural abscess; spine infection; opioid crisis

$\mathrm{O}$ PIOID abuse in the United States is becoming an epidemic and the subject of much media coverage. It was classified as a public health emergency by the Department of Health and Human Services (HHS) in 2017. Misuse of prescription opioids has been increasing since the 1990s ${ }^{15}$ more than 42,000 Americans died of opioid overdose in 2016. ${ }^{17}$ Furthermore, there is a direct link between prescription opioid use and intravenous drug use, notably heroin. ${ }^{16,20}$ In 2016, nearly 1 million Americans used heroin, 170,000 of them for the first time. ${ }^{2}$

Efforts to curb the opioid epidemic are being undertak- en both at the federal and statewide levels. Nationally, the HHS has released a 5-point strategy for fighting the opioid crisis. ${ }^{24}$ Locally, many states have addressed the issue by establishing opioid-prescribing restrictions. Louisiana was one such state, putting prescribing restrictions in place in early 2017. Prior to this, Louisiana had one of the highest opioid prescribing rates in the country, with 103 prescriptions per 100 people in 2015.22

Intravenous drug abuse (IVDA) is noteworthy to neurosurgeons, as it is a well-known risk factor for spinal epidural abscess (SEA), a neurosurgical emergency. This has

ABBREVIATIONS AIS = American Spinal Injury Association Impairment Scale; IVDA = intravenous drug abuse; MRSA = methicillin-resistant Staphylococcus aureus; MSSA = methicillin-sensitive $S$. aureus; SEA = spinal epidural abscess. ACCOMPANYING EDITORIAL DOI: 10.3171/2018.10.FOCUS18576.

SUBMITTED August 31, 2018. ACCEPTED October 12, 2018. INCLUDE WHEN CITING DOI: 10.3171/2018.10.FOCUS18449. 
been described for some time, with Koeppel et al. presenting a series of 18 patients in the 1980s with IVDA-associated SEA. ${ }^{18}$ While diagnosis and treatment methods have evolved since that time, IVDA-associated SEA remains a challenging entity for clinicians. IVDA-associated spinal infections have been increasing, with a 2018 study by Blecher et al. showing a 3-fold increase in Washington state over the last 15 years. ${ }^{7}$

The patient population with IVDA-associated SEA is notorious for low compliance with medical care and poor

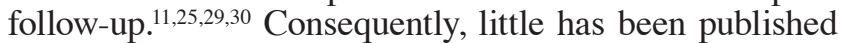
specifically examining this group. We sought to examine a series of IVDA-associated SEAs from our tertiary-care, safety-net hospital in Southeastern Louisiana.

\section{Methods}

This retrospective chart review was approved by our institutional review board. The study period was July 2013 through July 2018. Patients at our tertiary-care, safety-net hospital (Interim LSU Hospital \& University Medical Center New Orleans) were reviewed. Patients were queried for epidural abscesses using billing codes. A keyword search of "epidural abscess" within the radiology PACS (picture archiving and communication system) was also performed to ensure capture of all potential patients.

Charts were reviewed, and patients with recent intravenous drug use as a risk factor for epidural abscess were selected. These charts were reviewed for patient demographics, neurological examination findings, surgical intervention, perioperative complications, and outcome. Neurological examination findings were categorized according to American Spinal Injury Association Impairment Scale (AIS) with grades A-E assigned based on review of the initial presentation documentation. In patients who underwent fusion, fusion status was determined by either thin-slice CT or dynamic radiography.

Surgical intervention, both whether to intervene and which approach to use, was determined on a case-by-case basis by the attending neurosurgeon. Early surgery was defined as within 24 hours of presentation to the hospital, while late surgery was more than 24 hours after presentation. All cases were managed collaboratively with the internal medicine and infectious disease services.

The opioid prescribing policy for the state of Louisiana was obtained by querying the Louisiana Department of Health website..$^{19}$ Louisiana drug use statistics were obtained by querying the Louisiana Department of Health website and the Center for Disease Control and Prevention website. ${ }^{3,19}$ The yearly incidence of epidural abscesses related to intravenous drug use was calculated using the total number of cases seen at our institution per 12 months. Comparison of the rate of epidural abscesses before and after Louisiana instituted opioid-prescribing restrictions was done using Fisher's exact test.

Statistical analysis was performed using Microsoft Excel and SPSS; $p<0.05$ was considered statistically significant.

\section{Results}

A total of 45 patients presented with an epidural ab-
TABLE 1. Demographics of 45 patients with IVDA-associated SEAs

\begin{tabular}{cc}
\hline \multicolumn{1}{c}{ Variable } & Value \\
\hline Mean age (range), yrs & $47.1(25-71)$ \\
\hline No. of males (\%) & $34(75.6)$ \\
\hline Insurance, $\mathrm{n}(\%)$ & $30(66.7)$ \\
\hline Medicaid & $7(15.6)$ \\
\hline Medicare & $3(6.7)$ \\
\hline Uninsured & $2(4.4)$ \\
\hline Commercial & $3(6.7)$ \\
\hline Prisoner & $1(2.2)$ \\
\hline Initial AlS grade, $\mathrm{n}(\%)$ & $2(4.4)$ \\
\hline A & $6(13.3)$ \\
\hline B & $12(26.7)$ \\
\hline C & $24(53.3)$ \\
\hline D & \\
\hline E & $16(35.6)$ \\
\hline Spinal area, $\mathrm{n}(\%)^{*}$ & $10(28.6)$ \\
\hline Cervical & $22(48.9)$ \\
\hline Thoracic & $25.1(2-90)$ \\
\hline Lumbar & $31(68.9)$ \\
\hline Mean duration of pain (range), days & \\
\hline Underwent surgery, $\mathrm{n}(\%)$ & \\
\hline
\end{tabular}

* Spinal areas involved total to more than $100 \%$ because of patients with abscesses in multiple areas.

scess secondary to intravenous drug abuse. See Table 1 for a summary of demographics for this group. The ages ranged from 25 to 71 years, with a mean of 47 years; 34 patients (75.6\%) were male. Medicaid was the payer in the majority of cases. Twenty-four patients $(53.5 \%)$ presented without any neurological deficit, while 12 presented with AIS grade D, 6 with AIS grade C, and 2 with AIS grade $\mathrm{B}$ injuries, and 1 had a complete spinal cord injury. The lumbar spine was most commonly affected, with 22 patients having an abscess in that region; in 16 patients the cervical spine was involved, and in 10 the thoracic spine was involved. Two patients had undergone previous spine surgery, both involving instrumented fusions. These 2 patients both presented with abscesses associated with their prior instrumentation.

Thirty-one patients underwent surgical intervention. See Table 2 for a summary of the surgical characteristics for these patients. Sixteen patients (51.5\% of surgical patients) underwent early surgery (within 24 hours). Twentytwo patients underwent surgery for a neurological deficit and 12 for failure of medical treatments. Medical therapy failed in 3 patients, and they developed new neurological deficits. Twenty-nine patients had a decompression and 19 of those also underwent fusion. Two patients with previous instrumented fusions underwent surgery to remove their instrumentation. They had both shown bony fusion on CT scans, and medical therapy to treat persistent abscesses had failed.

Thirteen patients (41.9\%) had perioperative complications. Four patients required a return to the operating 
TABLE 2. Characteristics of the 31 patients who underwent surgery for IVDA-associated SEAs

\begin{tabular}{lc}
\hline \multicolumn{1}{c}{ Variable } & No. of Patients $(\%)$ \\
\hline Decompression & $29(93.5)$ \\
\hline Decompression \& fusion & $19(61.3)$ \\
\hline Instrumentation removal only & $2(6.5)$ \\
\hline Surgical indication & $22(71.0)$ \\
\hline Neurological deficit & $12(38.7)$ \\
\hline Failed medical therapy & \\
\hline Fusion level & 13 \\
\hline Cervical & 4 \\
\hline Thoracic & 2 \\
\hline Lumbar & 4 \\
\hline Fusion approach & 8 \\
\hline Anterior only & 6 \\
\hline Posterior only & \\
\hline Circumferential & $4(12.9)$ \\
\hline Periop complications & $3(9.7)$ \\
\hline Washout for continued infection & $3(9.7)$ \\
\hline Short-term instrumentation failure & $3(9.7)$ \\
\hline Intraop cardiac arrest & $5(26.3)$ \\
\hline Death & $3(15.8)$ \\
\hline Fusion status & $11(57.9)$ \\
\hline Confirmed fusion & \\
\hline Confirmed pseudarthrosis & \\
\hline Insufficient follow-up & \\
\hline
\end{tabular}

Total numbers for surgical indication add up to more than $100 \%$ due to $3 \mathrm{pa}-$ tients in whom medical therapy failed and a new neurological deficit developed during hospitalization.

room for continued infection and fluid collections at the surgical site. Three had short-term instrumentation failures requiring revision. Three patients had intraoperative cardiac arrest, of whom 2 died postoperatively. One additional patient died of sepsis postoperatively, giving a mortality rate of $6.7 \%$.

Of the patients undergoing decompression without fusion, all operations involved the thoracolumbar spine and a posterior approach was taken. Of the patients undergoing a decompression with fusion, 13 were cervical, 4 thoracic, and 2 lumbar. Four patients underwent an anterior approach only (all cervical). Eight had a posterior-only approach, and 6 underwent circumferential fusion.

Of the 21 patients who presented with a neurological deficit, 6 (28.6\%) had improved at discharge. Four patients (8.9\% of the total cohort) had worsening neurological deficits at discharge (including 2 patients who presented without any deficit). Patients who underwent surgery within 24 hours of presentation, on average, gained 0.2 grades on the AIS scale and those who underwent surgery after 24 hours declined 0.3 grades. This difference was not statistically significant $(\mathrm{p}=0.181)$. When comparing patients undergoing surgery within 24 hours of the onset of their weakness, there was a greater trend toward neurological recovery, with a gain of 0.5 AIS grades versus a loss of
TABLE 3. Outcomes of patients presenting with IVDA-associated SEAs

\begin{tabular}{lc}
\hline \multicolumn{1}{c}{ Variable } & Value \\
\hline Improved AIS grade at discharge, $\mathrm{n}(\%)$ & $6(28.6)^{*}$ \\
\hline Worse AIS grade at discharge, $\mathrm{n}(\%)$ & $4(8.9)$ \\
\hline Bacteria isolated, $\mathrm{n}(\%)$ & $26(57.8)$ \\
\hline MRSA & $13(28.9)$ \\
\hline MSSA & $2(4.4)$ \\
\hline Streptococcus spp. & $1(2.2)$ \\
\hline Propionibacterium acnes & $3(6.7)$ \\
\hline No growth & $27.6(4-90)$ \\
\hline Mean LOS (range), days & $17(37.8)$ \\
\hline Discharge location, $\mathrm{n}(\%)$ & $9(20.0)$ \\
\hline Long-term acute care & $4(8.9)$ \\
\hline Home & $3(6.7)$ \\
\hline Skilled nursing & $6(13.3)$ \\
\hline Rehab & $3(6.7)$ \\
\hline Left AMA & $3(6.7)$ \\
\hline Prison &
\end{tabular}

AMA = against medical advice; LOS = length of stay.

* Percentage is based on the number of patients presenting with a deficit.

0.2 AIS grades. This was still not statistically significant $(\mathrm{p}=0.068)$.

Length of stay ranged from 4 to 90 days, with an average of 27.6 days. Long-term acute care was the most common discharge destination, with 17 patients (37.8\%) discharged there. Nine patients were discharged home, 4 to skilled nursing facilities, 3 to rehabilitation facilities, and 3 to custody. Six patients (13.3\%) left against medical advice. See Table 3 for a summary of outcomes.

The most common bacterium isolated from intraoperative cultures, peripheral source, or interventional radiology biopsy was methicillin-resistant Staphylococcus aureus (MRSA; 26 patients [57.8\%]). Methicillin-sensitive Staphylococcus aureus (MSSA) was present in 13 patients (28.9\%), while streptococcal species were present in 2 patients and Propionibacterium acnes in 1 patient; 3 patients did not have any bacteria isolated.

Follow-up for these patients is extremely poor, as 13 patients $(28.9 \%)$ did not have any follow-up. Only 23 patients followed up with their scheduled clinic visits, despite efforts to contact the remaining patients. An additional 9 patients stayed in contact with healthcare providers in our system by return visits to the emergency department. Fourteen patients (43.8\%) who did undergo follow-up had confirmation of continued intravenous drug use. Only 8 of the 19 fusion patients had sufficient follow-up to determine fusion status. Five had confirmed fusion, and 3 had confirmed pseudarthrosis. See Table 4 for our follow-up statistics.

Drug-related deaths in Louisiana increased every year over our study period. ${ }^{2}$ The rate of epidural abscesses also showed an increasing trend line, although this rate is increasing more sharply than that of drug deaths (Fig. 
TABLE 4. Follow-up statistics for our patient population

\begin{tabular}{lc}
\hline \multicolumn{1}{c}{ Variable } & Value \\
\hline Followed up in clinic, $\mathrm{n}(\%)$ & $23(51.1)$ \\
\hline Followed up in emergency department, $\mathrm{n}(\%)$ & $9(20.0)$ \\
\hline Average follow-up, mos & 10.6 \\
\hline Confirmed still using intravenous drugs, $\mathrm{n}(\%)^{*}$ & $14(43.8)$ \\
\hline
\end{tabular}

${ }^{*}$ Percentage is based on the number of patients with any follow-up.

1). Opioid-prescribing restrictions were instituted by the Louisiana Department of Health on January 10, 2017. The restriction initially comprised a 15-day supply limit for Medicaid fee-for-service patients. ${ }^{19}$ The restrictions were expanded to other patient populations over the rest of the year. The rate of epidural abscesses before the restrictions on Medicaid fee-for-service patients were put into place was 0.54 cases per month. This increased to 1.15 cases per month after the restrictions were placed (Table 5). This increase was statistically significant $(\mathrm{p}=0.017)$.

\section{Illustrative Case}

This 55-year-old woman presented with 8 days of fever and neck pain and a day of worsening left-sided weakness and paresthesias. The patient endorsed recent intravenous drug use. Her strength was diminished throughout the left upper and lower extremities, and she could not ambulate. MRI showed an anterior epidural abscess from C5 to C7 (Fig. 2). She was scheduled for surgery but refused to consent. With her worsening clinical examination, the patient opted for surgical intervention 1 day later and underwent a C6-7 corpectomy, drainage of the abscess, and anterior fusion at C5-T1 with posterior instrumentation at C5-T2. Her wound grew out MRSA, and the patient was treated with vancomycin and rifampin. She had a 25-day hospital stay before being discharged to a skilled nursing facility. She proceeded to have multiple emergency department visits over the following year, and, although she made her clinic follow-up visits, she endorsed continued intravenous drug use. On her last neurosurgery visit, 1 year postoperatively, she complained of continued axial and neuropathic pain but had near-complete resolution of her preoperative weakness. Her CT scan at that time showed solid bony arthrodesis (Fig. 3).

\section{Discussion}

Our series of 45 patients with IVDA-associated SEA reiterates many of the follow-up and compliance challenges faced by clinicians in other series. Wang et al. published a series of 51 patients presenting with IVDA-associated spinal infections. ${ }^{29}$ They did not specify patients with SEA. Forty-four patients in their cohort underwent surgery. Their population showed similar difficulty with compliance. Notably, $72.5 \%$ of their patients were apprehended using intravenous drugs while in the hospital. None of their patients maintained follow-up at 2 years. Ziu et al. reviewed 26 patients with IVDA-associated SEA. ${ }^{30}$ Twenty-two of these patients underwent surgery. Their patients had a slightly better follow-up, with $64.7 \%$ making

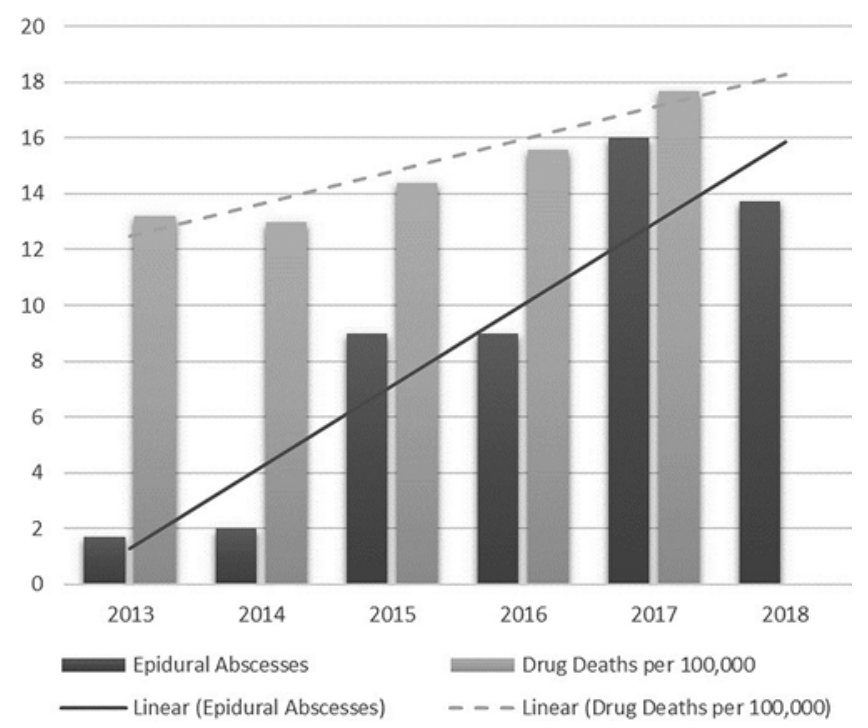

FIG. 1. Comparison of the rate of drug-related deaths in Louisiana (per 100,000 citizens) with the yearly incidence of epidural abscesses seen at our institution.

a 1-year clinic follow-up appointment. The series by Chuo et al. out of Taiwan showed much better follow-up rates $(100 \%)$ than the 2 American studies, but only included 3 cases of IVDA-associated SEA. ${ }^{11}$ In our series, only $51.1 \%$ of patients made 1 follow-up clinic visit. Of the patients who remained in contact with our healthcare system (either via clinic appointments or emergency department visits), $43.8 \%$ were still using intravenous drugs.

SEA, regardless of association with IVDA, is considered a neurosurgical emergency. It can be treated medically or surgically. The majority of our patients (68.9\%) underwent neurosurgical intervention. The indications were neurological compromise or failure of medical management, which align with the existing literature. , $^{1,4-6,8,9,11,13 \text {, }}$ $18,21,23,26,27,29,30$ Our complication rates are similar to those of other studies covering this patient population. The study by Wang et al. reported several early hardware failures $(15.9 \%)$ and recurrent infections $(4.5 \%)$ requiring washout. ${ }^{29}$ Our rates were similar at $9.7 \%$ and $12.9 \%$, respectively. Our in-hospital mortality rate was $6.7 \%$, and the overall complication rate was $41.9 \%$. This reflects the comorbidities that complicate care of these patients.

The majority of our patients $(77.8 \%)$ had no change in their neurological examination results at discharge; $28.6 \%$ of the patients who presented with a deficit had improvement by the time of discharge. This contrasts the findings of Wang et al. (69\% with improvement) ${ }^{29}$ and Chuo et al. (100\% with improvement). ${ }^{11}$

A possible explanation for our lower rate of improvement is the delays in medical care that many of our patients experienced. Twelve of our patients with deficits had neurological symptoms for 5 or more days before undergoing surgical intervention. Reasons for delays included failure to seek medical attention, noncompliance with physician advice, and comorbidities precluding surgical intervention (systemic sepsis or coagulopathy). Patients who underwent surgery within 24 hours of onset of neurological deficits 
TABLE 5. Number of SEAs at our institution before and after opioid-prescribing restrictions were enacted by the Louisiana Department of Health

\begin{tabular}{ccccc}
\hline $\begin{array}{c}\text { Opioid } \\
\text { Restrictions }\end{array}$ & Dates & $\begin{array}{c}\text { Total } \\
\text { Cases }\end{array}$ & $\begin{array}{c}\text { Cases/ } \\
\text { Mo }\end{array}$ & $\begin{array}{c}p \\
\text { Value* }\end{array}$ \\
\cline { 1 - 4 } No & July 2013-January 2017 & 22 & 0.54 & \multirow{2}{*}{0.017} \\
\cline { 1 - 4 } Yes & February 2017-July 2018 & 23 & 1.15 & \\
\hline * Comparison made with Fisher's exact test. & & &
\end{tabular}

${ }^{*}$ Comparison made with Fisher's exact test.

did have a slightly better chance at recovery of neurological function than those undergoing delayed surgery, but this result was not statistically significant. Of the 4 patients who had worse neurological examination results at discharge, 2 were initially treated medically and only underwent surgery after failure and new-onset deficits. The timing of surgical intervention in epidural abscesses is still one that is debated, although the literature does tend to favor early intervention. ${ }^{4,5,13}$ Our results also appear to favor early surgery, especially in light of the patients who had worse examination findings at discharge after medical therapy had failed.

The surgical approach for spine infections is also a controversial topic. Recent studies have allayed some of the fears regarding placing instrumentation in an infected field. Notably, the 2014 study by Bydon et al. showed no increased complication or reoperation rate for instrumented versus uninstrumented surgery on spine infections..$^{10}$ However, only $15 \%$ of the patients in that study were intravenous drug users. Meanwhile, Wadhwa et al. showed that circumferential surgery for cervical osteomyelitis is associated with more complications than when it is done for myelopathy. ${ }^{28}$ It is difficult to determine the success of fusion in our population with such limited follow-up. We found that only 5 of 8 patients with adequate follow-up achieved bony fusion. Notably, these fusions were all in the cervical spine, where instrumentation is generally considered necessary. Of the patients with confirmed pseudarthrosis, 1 each had undergone lumbar posterior fusion, thoracic posterior fusion, and circumferential cervicothoracic fusion.

Regarding the causative pathogen, our series shows a much higher rate of MRSA than prior publications; 57.8\% of our patients grew MRSA from intraoperative cultures, biopsy, or peripheral blood draws. This rate is higher than the MRSA rates in any of the prior studies we reviewed, both in IVDA- and non-IVDA-associated spine infections. . $13,30,31$ This is likely a reflection of our patient population, as a strain of pathogen that is introduced into a network of intravenous drug abusers can create a community reservoir of that pathogen..$^{14}$

As the only safety-net hospital in southeastern Louisiana, we are confident that our data capture most IVDAassociated SEAs in the metropolitan area. Our data show that there was a significant increase in the rate of epidural abscesses after Louisiana instituted restrictions on prescription opioids. One explanation for this would be that more people are turning to injectable opiates since they can no longer obtain pills. Another explanation is that this reflects the overall increasing trend, and our cutoff date is
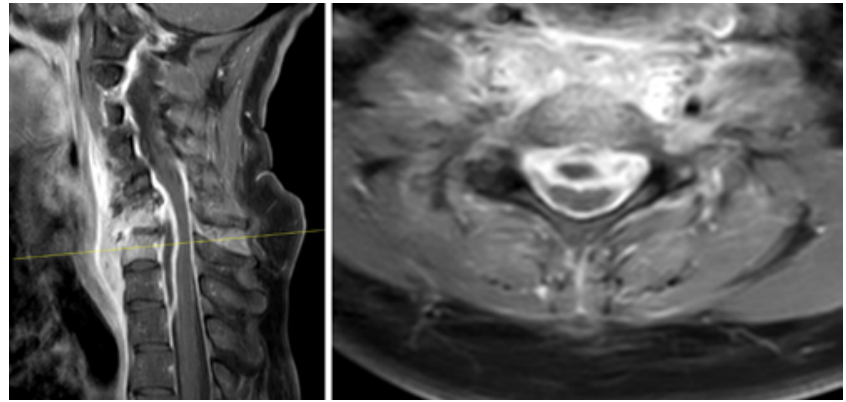

FIG. 2. Sagittal (left) and axial (right) T1-weighted contrast-enhanced MRI scans demonstrating a large dorsal abscess of the cervical spine.

an arbitrary divide. Our increasing trend line does correlate with the increasing IVDA-associated spinal infections found by Blecher et al.

Irrespective of the reason for its increasing rate, IVDAassociated SEA remains a significant public health issue. As we have shown here, these patients are extremely challenging to treat and consume large amounts of healthcare resources. We are not advocating for loosening opioid prescribing restrictions. Rather, this series highlights the need for better prevention efforts and community outreach to ensure timely access to care and compliance with follow-up. Simply being publicly funded in southeastern Louisiana is a risk factor for neurological infections, ${ }^{12}$ so this issue should be a high priority for policy makers.

Our study has many limitations, most notably the lack of consistent follow-up. Additionally, it is subject to the standard bias inherent in a retrospective review. However, even given these limitations, this series represents one of the largest covering IVDA-associated SEA.

\section{Conclusions}

IVDA-associated SEA is a challenging disease entity. Our patient population showed poor compliance and follow-up. Our series did demonstrate that early surgery can lead to neurological recovery. Additionally, instrumented fusion in the cervical spine can lead to bony arthrodesis
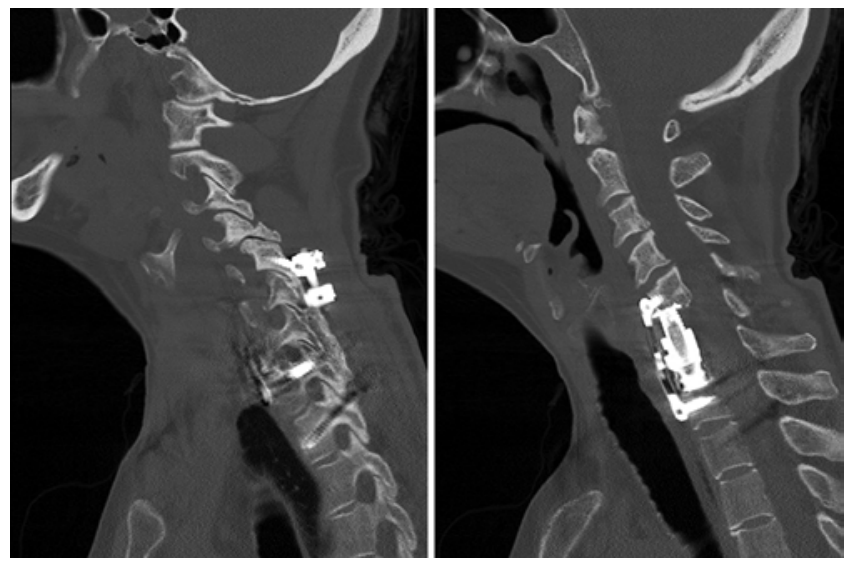

FIG. 3. CT scan obtained 1 year postoperatively, showing bony arthrodesis and stable instrumentation. 
with fewer hardware failures than elsewhere in the spine. In addition, the rates of MRSA infection appear to be higher in our population than previously described in the literature. Lastly, our rate of IVDA-associated SEA has increased over the past few years. This increase correlates with state restrictions on opioid prescriptions.

\section{Acknowledgments}

We acknowledge Ray Navarro and Erin Fannin for their assistance with data collection.

\section{References}

1. Adogwa O, Karikari IO, Carr KR, Krucoff M, Ajay D, Fatemi P, et al: Spontaneous spinal epidural abscess in patients 50 years of age and older: a 15-year institutional perspective and review of the literature: clinical article. J Neurosurg Spine 20:344-349, 2014

2. Ahrnsbrak R, Bose J, Hedden SL, Lipari RN, Park-Lee E: Key Substance Use and Mental Health Indicators in the United States: Results from the 2016 National Survey on Drug Use and Health. (HHS Publication No. SMA 17-5044, NSDUH Series H-52). Rockville, MD: Center for Behavioral Health Statistics and Quality, 2017 (https://www. samhsa.gov/data/sites/default/files/NSDUH-FFR1-2016/ NSDUH-FFR1-2016.htm) [Accessed November 9, 2018]

3. Ahmad FB, Rossen LM, Spencer MR, Warner M, Sutton P: Provisional Drug Overdose Death Counts. Atlanta: National Center for Health Statistics, 2018 (https://www. cdc.gov/nchs/nvss/vsrr/drug-overdose-data.htm) [Accessed November 9, 2018]

4. Alton TB, Patel AR, Bransford RJ, Bellabarba C, Lee MJ, Chapman JR: Is there a difference in neurologic outcome in medical versus early operative management of cervical epidural abscesses? Spine J 15:10-17, 2015

5. Arko L IV, Quach E, Nguyen V, Chang D, Sukul V, Kim BS: Medical and surgical management of spinal epidural abscess: a systematic review. Neurosurg Focus 37(2):E4, 2014

6. Artenstein AW, Friderici J, Holers A, Lewis D, Fitzgerald J, Visintainer P: Spinal epidural abscess in adults: a 10-year clinical experience at a tertiary care academic medical center. Open Forum Infect Dis 3:ofw191, 2016

7. Blecher R, Yilmaz E, Drazin D, Oskouian RJ, Chapman JR: Recent increase in the rate of spinal infections may be related to growing substance-use disorder in the state of Washington: wide population-based analysis of the Comprehensive Hospital Abstract Reporting System (CHARS) database. Spine (Phila Pa 1976) [epub ahead of print], 2018

8. Boody BS, Jenkins TJ, Maslak J, Hsu WK, Patel AA: Vertebral osteomyelitis and spinal epidural abscess: an evidencebased review. J Spinal Disord Tech 28:E316-E327, 2015

9. Butler JS, Shelly MJ, Timlin M, Powderly WG, O’Byrne JM: Nontuberculous pyogenic spinal infection in adults: a 12-year experience from a tertiary referral center. Spine (Phila Pa 1976) 31:2695-2700, 2006

10. Bydon M, De la Garza-Ramos R, Macki M, Naumann M, Sciubba DM, Wolinsky JP, et al: Spinal instrumentation in patients with primary spinal infections does not lead to greater recurrent infection rates: an analysis of 118 cases. World Neurosurg 82:e807-e814, 2014

11. Chuo CY, Fu YC, Lu YM, Chen JC, Shen WJ, Yang CH, et al: Spinal infection in intravenous drug abusers. J Spinal Disord Tech 20:324-328, 2007

12. Eggart MD, Greene C, Fannin ES, Roberts OA: A 14-year review of socioeconomics and sociodemographics relating to intracerebral abscess, subdural empyema, and epidural abscess in southeastern Louisiana. Neurosurgery 79:265-269, 2016
13. Ghobrial GM, Beygi S, Viereck MJ, Maulucci CM, Sharan A, Heller J, et al: Timing in the surgical evacuation of spinal epidural abscesses. Neurosurg Focus 37(2):E1, 2014

14. Gwizdala RA, Miller M, Bhat M, Vavagiakis P, Henry C, Neaigus A, et al: Staphylococcus aureus colonization and infection among drug users: identification of hidden networks. Am J Public Health 101:1268-1276, 2011

15. Jordan AE, Blackburn NA, Des Jarlais DC, Hagan H: Pastyear prevalence of prescription opioid misuse among those 11 to 30 years of age in the United States: a systematic review and meta-analysis. J Subst Abuse Treat 77:31-37, 2017

16. Jordan AE, Jarlais DD, Hagan H: Prescription opioid misuse and its relation to injection drug use and hepatitis $C$ virus infection: protocol for a systematic review and meta-analysis. Syst Rev 3:95, 2014

17. Kochanek K, Murphy S, Xu J, Arias E: Mortality in the United States, 2016. NCHS Data Brief No. 293. Hyattsville, MD: National Center for Health Statistics, 2017 (https://www. cdc.gov/nchs/data/databriefs/db293.pdf) [Accessed November 9, 2018]

18. Koppel BS, Tuchman AJ, Mangiardi JR, Daras M, Weitzner I: Epidural spinal infection in intravenous drug abusers. Arch Neurol 45:1331-1337, 1988

19. Kuy S, Steele J: Louisiana Fee for Service (FFS) Medicaid Pharmacy Opioid Quantity Limits. Baton Rouge: Louisiana Department of Health, 2016 (https://www. lamedicaid.com/provweb1/pharmacy/FFS_15_day_opioid_ quantity_limit_provider_memo.pdf) [Accessed November 9 , 2018]

20. Mars SG, Bourgois P, Karandinos G, Montero F, Ciccarone D: "Every 'never' I ever said came true": transitions from opioid pills to heroin injecting. Int J Drug Policy 25:257266, 2014

21. Mohamed AS, Yoo J, Hart R, Ragel BT, Hiratzka J, Hamilton DK, et al: Posterior fixation without debridement for vertebral body osteomyelitis and discitis. Neurosurg Focus 37(2):E6, 2014

22. National Institutes of Health: Louisiana opioid summary. National Institute on Drug Abuse. (https://www.drugabuse. gov/drugs-abuse/opioids/opioid-summaries-by-state/ louisiana-opioid-summary) [Accessed November 9, 2018]

23. Patel AR, Alton TB, Bransford RJ, Lee MJ, Bellabarba CB, Chapman JR: Spinal epidural abscesses: risk factors, medical versus surgical management, a retrospective review of 128 cases. Spine J 14:326-330, 2014

24. Price TE: Secretary Price Announces HHS strategy for fighting opioid crisis. Department of Health and Human Services. April 19, 2017 (https://www.hhs.gov/about/ leadership/secretary/speeches/2017-speeches/secretary-priceannounces-hhs-strategy-for-fighting-opioid-crisis/index.html) [Accessed November 9, 2018]

25. Ries R, Krupski A, West II, Maynard C, Bumgardner K, Donovan D, et al: Correlates of opioid use in adults with selfreported drug use recruited from public safety-net primary care clinics. J Addict Med 9:417-426, 2015

26. Shweikeh F, Saeed K, Bukavina L, Zyck S, Drazin D, Steinmetz MP: An institutional series and contemporary review of bacterial spinal epidural abscess: current status and future directions. Neurosurg Focus 37(2):E9, 2014

27. Tuchman A, Pham M, Hsieh PC: The indications and timing for operative management of spinal epidural abscess: literature review and treatment algorithm. Neurosurg Focus 37(2):E8, 2014

28. Wadhwa R, Mummaneni PV, Lau D, Le H, Chou D, Dhall SS: Perioperative morbidity and mortality comparison in circumferential cervical fusion for osteomyelitis versus cervical spondylotic myelopathy. Neurosurg Focus 37(2):E7, 2014

29. Wang Z, Lenehan B, Itshayek E, Boyd M, Dvorak M, Fisher $\mathrm{C}$, et al: Primary pyogenic infection of the spine in intrave- 
nous drug users: a prospective observational study. Spine (Phila Pa 1976) 37:685-692, 2012

30. Ziu M, Dengler B, Cordell D, Bartanusz V: Diagnosis and management of primary pyogenic spinal infections in intravenous recreational drug users. Neurosurg Focus 37(2):E3, 2014

\section{Disclosures}

The authors report no conflict of interest concerning the materials or methods used in this study or the findings specified in this paper.

\section{Author Contributions}

Conception and design: DiGiorgio, Morrow, Robichaux, Crutcher, Tender. Acquisition of data: DiGiorgio, Stein, Morrow, Robichaux. Analysis and interpretation of data: all authors. Drafting the article: all authors. Critically revising the article: all authors. Reviewed submitted version of manuscript: DiGiorgio, Stein, Morrow, Robichaux, Crutcher. Approved the final version of the manuscript on behalf of all authors: DiGiorgio. Statistical analysis: DiGiorgio. Administrative/technical/material support: Tender. Study supervision: Tender.

\section{Correspondence}

Anthony M. DiGiorgio: Louisiana State University Health Sciences Center, New Orleans, LA. adigi2@lsuhsc.edu. 